\section{INFORMAÇÃO DO CD DA SPQ}

O Conselho Directivo (CD) da SPQ reuniu no passado dia 8 de Dezembro de 2007 nas instalações do Departamento de Química da Universidade de Aveiro, com uma ordem de trabalhos bastante longa, com 14 pontos, abarcando as diversas componentes da vida da Sociedade - e reflectindo, aliás, a amplitude da sua actividade actual:

1 - Situação Geral da Sociedade

2 - Funcionamento da Sede

3 - Situação Financeira

4 - Sócios

5 - Delegações Regionais

6 - Divisões e Grupos

7 - Encontros da SPQ

8 - Presença na Internet

9 - Publicações nacionais e internacionais

10 - Olimpíadas da Química

11 - Prémios

12 - Química em Portugal

13 - Relações Internacionais

14 - Orçamento e Plano 2008 / Previsão 2009

A título ilustrativo, o ponto 2 incluía duas alíneas, relativas à distribuição de tarefas entre os funcionários da SPQ e à mudança da Sede em 2008, enquanto o ponto 12 previa 8 tópicos, desde as relações com o Ministério da Educação (exames nacionais e avaliação dos manuais escolares), passando pelas actividades do Programa Atracção Química e indo até à proposta da IUPAC para declarar 2011 como Ano Internacional da Química.
Infelizmente, a reunião iniciou-se tardiamente (devido a um inoportuno atraso dos comboios Lisboa-Aveiro) e foi necessário concentrar a discussão nos pontos mais importantes e urgentes. As questões de menor urgência ficaram agendadas para uma reunião a realizar no início de 2008.

Como deliberações mais relevantes e de impacto imediato junto dos sócios, salientam-se as seguintes, já oportunamente divulgadas através da "newsletter" por correio electrónico que a SPQ envia aos seus sócios sempre que as notícias o justificam ${ }^{1}$ :

\section{Criação do Grupo de Química Terapêutica}

Foi aprovada por unanimidade a proposta de criação do Grupo de Química Terapêutica e formalizada a inscrição da SPQ como membro da European Federation of Medicinal Chemistry (EFMC). O primeiro congresso do Grupo está previsto para Novembro de 2008.

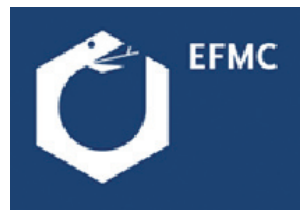

\section{Criação do Grupo de Químicos Jovens}

Foi aprovada por unanimidade a criação do Grupo de Químicos Jovens, que deverá realizar o seu primeiro congresso em finais de 2008.

Através deste Grupo a SPQ passará também a fazer parte da European Young Chemists Network da EuCheMS (EYCN).

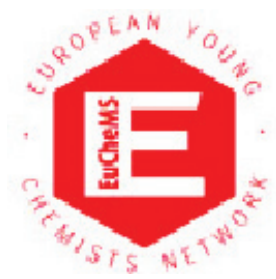

ALteraÇÃo dAS REGRAS dE INSCRIÇÃo NA SPQ

O estatuto de "Sócio estudante" foi alargado, passando a incluir os estudantes até ao $2^{\circ}$ Ciclo universitário.

Tendo em conta o crescimento da estrutura da SPQ, foi aprovado alterar de 3 para 6 o número de Divisões ou Grupos a que um sócio pode estar inscrito gratuitamente (brevemente activo na "área de sócio").

A SPQ conta actualmente com $8 \mathrm{Di}$ visões e 10 Grupos:

\section{Divisões}

Catálise e Materiais Porosos

Ciências da Vida

Ensino e Divulgação da Química

Química Alimentar

Química Analítica

Química Inorgânica

Química Orgânica

Química-Física

\section{Grupos}

Colóides, Polímeros e Interfaces Cromatografia

Fotoquímica

De acordo com o artigo $31^{\circ}$ dos Estatutos da SPQ, o "Conselho Directivo é constituído por: a) Presidente; b) Vice-presidente; c) Secretário-Geral; d) Dois Secretários-Gerais Adjuntos; e) Tesoureiro; f) Presidentes de todas as Delegações Regionais". Este Conselho tem um número de competências alargadas, enumeradas no artigo $33^{\circ}$ e específicadas em alguns outros ao longo dos Estatutos. Algumas destas competências são tradicionalmente delegadas à Comissão Executiva, nos termos do mesmo artigo $33^{\circ}$, como, por exemplo, a admissão de sócios efectivos (art. $5^{\circ}$ ), os descontos para sócios nas realizações da sociedade (art. $9^{\circ}$ ) e a elaboração do Relatório e Contas anual (art. $33^{\circ}$ - h). São competências tradicionamente não-delegadas "a criação ou extinção de Divisões ou Grupos" (art. $33^{\circ}$ - m) e "a definição das quotas mínimas anuais" (art. $7^{\circ}$ ).

1 Evidentemente, só os sócios com endereço de 'email' actualizado estão a receber esta informação. O endereço pode ser actualizado directamente na "área de sócio" do portal SPQ ou enviando a informação para a Sede (sede@spq.pt). 


\section{Glúcidos}

História da Química

Química Industrial

Química Terapêutica / Medicinal Chemistry

Químicos Jovens

Radicais Livres

Ressonância Magnética

\section{QuOTAS PARA 2008}

Foi deliberado actualizar as quotas para 38 Euros em 2008 (23 Euros para estudantes até ao $2^{\circ}$ ciclo universitário), para garantir o necessário equilíbrio orçamental da Sociedade. Recorda-se que o valor da quota permanecia sem alteração desde o ano de 2002. Em compensação, aumentou-se a oferta de benefícios aos sócios (de que são exemplo o acesso gratuito ao "Ciênciapt.net" e os descontos "Texas Instruments") e houve consideráveis investimentos na melhoria do funcionamento da Sociedade.

\section{Orçamento para 2008}

Foi aprovado por unanimidade o orçamento da Sociedade para 2008, que prevê despesas e proveitos de 120.000 Euros. O orçamento foi construido com base nas contas de 2007 e nas expectativas de evolução para 2008 , garantindo $\mathrm{O}$ necessário equlíbrio financeiro. A verba de "Projectos e Melhoramentos", que permite ao Conselho Executivo enfrentar situações pontuais ao longo do ano, funciona também como uma salvaguarda para uma eventual quebra de receitas. De referir que os subsídios de entidades estatais - cuja fatia mais significativa se destina a apoiar as Olimpíadas de Química - têm um peso inferior a 22\% das receitas da SPQ.

Uma baixa percentagem da componente de subsídios estatais é normalmente considerada desejável como garantia de independência das sociedades científicas.

A este orçamento acresce um "orçamento extraordinário" respeitante ao processo de mudança de instalações da Sede, que se efectuará em 2008.
Os limites do orçamento extraordinário são definidos pela indemnização negociada com o comprador

do prédio e pelas verbas reservadas para esse efeito em anos anteriores.

\begin{tabular}{|c|c|c|c|}
\hline \multicolumn{4}{|c|}{ Sociedade Portuguesa de Química - Orçamento 2008} \\
\hline Despesas & Euros & Proveitos & Euros \\
\hline Sede (a) & 12.000 & Quotas & 45.000 \\
\hline Recursos Humanos (b) & 40.000 & Revistas Europeias (f) & 19.000 \\
\hline Boletim "Química" & 26.000 & Publicidade & 5.000 \\
\hline Olimpíadas de Química & $20.000^{(c)}$ & Subsídios Estatais (g) & 26.000 \\
\hline Representação Internacional (d) & 5.000 & Aplicações Financeiras & 3.000 \\
\hline Projectos e Melhoramentos (e) & 17.000 & Apoio "Encontros" (h) & 22.000 \\
\hline Total & 120.000 & Total & 120.000 \\
\hline
\end{tabular}

Notas:

(a) Instalações, despesas de funcionamento e expediente;

(b) Inclui dois funcionários e contrato com empresa de contabilidade;

(c) Excluindo despesas já assumidas pelas universidades participantes;

(d) Quotas e viagens indispensáveis (IUPAC, EuCheMS, EuChemSoc, EFMC);

(e) Valor máximo, a gerir pela Direcção na melhoria da actividade e visibilidade da $S P Q$;

(f) Dividendos da participação da SPQ na sociedade editorial EuChemSoc;

(g) Ministério da Educação (Olimpíadas), Ministério da Ciência (Funcionamento);

(h) Contribuições para despesas da Sede com divulgação/gestão/secretariado dos Encontros.
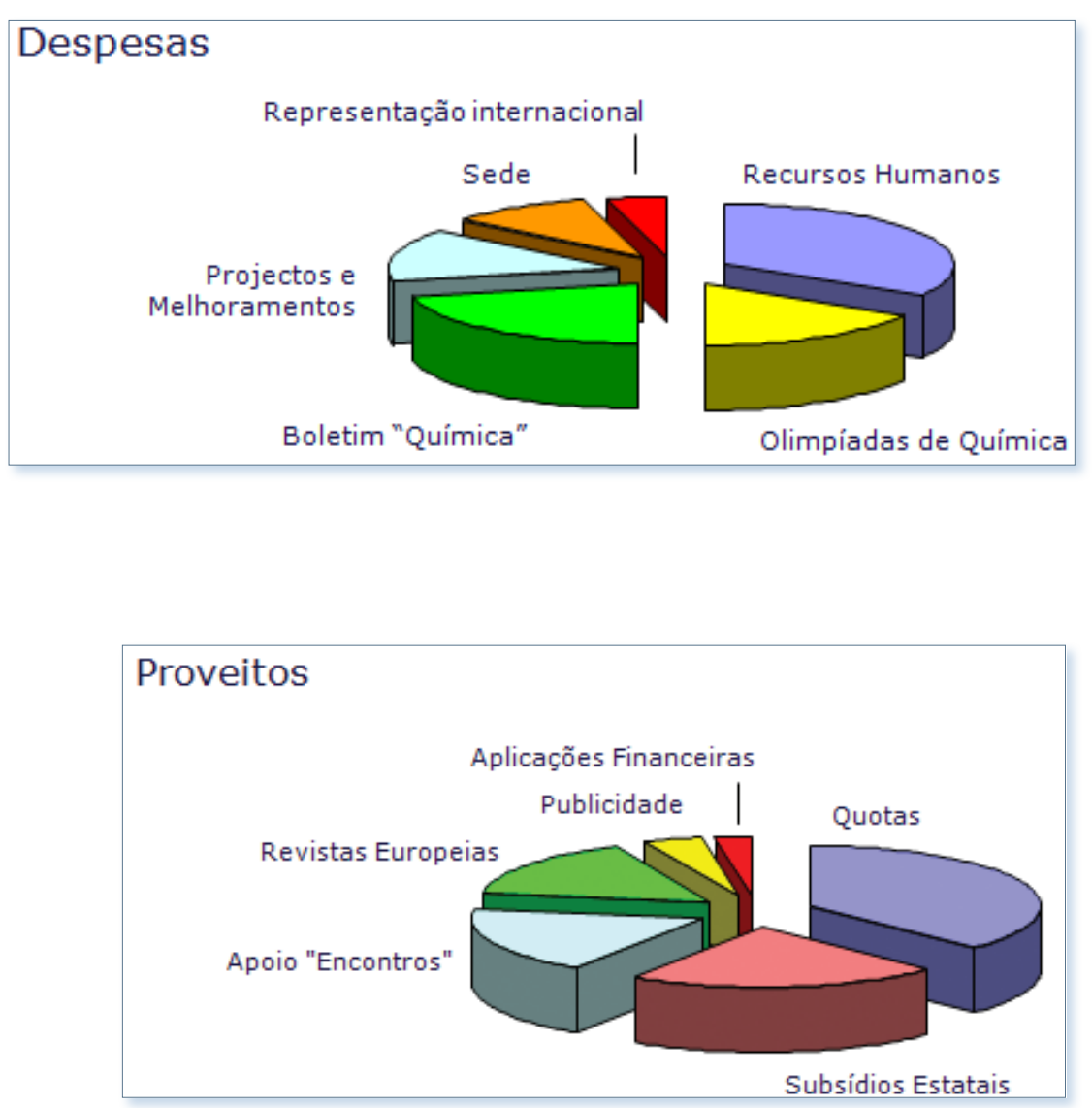